\title{
Avaliação do hemograma de ovinos em processo hemorrágico experimental agudo
}

\author{
Ovine hemogram evaluation during an induced acute experimental \\ hemorrhagic disorder
}

\author{
Denise Louise Howard, Luciano Pereira, Alessandra Sanchez, João Reinholz Netto, \\ Tomie Aparecida Madsuura, Hermes Raupp
}

\begin{abstract}
Resumo
A resposta eritrocitária e leucocitária de ovinos, submetidos à perda aguda de $20 \%$ do total de volume sangüíneo em relação ao peso corpóreo, foi avaliada e acompanhou-se a evolução do quadro durante 14 dias. Os valores hematimétricos decresceram significativamente a partir de $3 \mathrm{~h}$, com os valores mais baixos observados $24 \mathrm{~h}$ após a sangria, retornandose aos valores iniciais pré-sangria aos 12 dias. Houve aumento significativo dos reticulócitos entre 2 e 12 dias, o mesmo não ocorrendo em relação aos eritroblastos. No leucograma, observou-se uma inversão da relação linfócitos: neutrófilos durante 3 dias caracterizando o estresse provocado pela perda aguda de sangue. Eosinofilia e monocitose intermitentes foram observadas no decorrer do período da recuperação dos animais. Concluiu-se que a sangria de $20 \%$ do sangue total nos ovinos foi suficiente para provocar uma anemia aguda, permitindo avaliar a resposta hematopoiética desta espécie.
\end{abstract}

Palavras-chave: anemia hemorrágica; ovinos; hematologia.

\section{Introdução}

A anemia aguda por perda de sangue está associada a efeitos hemodinâmicos representados por variações no volume total sangüíneo e plasmático, bem como com alterações na sua composição. A avaliação da resposta eritrocitária e da resposta leucocitária nos processos hemorrágicos agudos tem sido investigada por vários autores com resultados diversos. Nesse sentido, o tema ainda é motivo de debates e discussões por se tratar de um assunto complexo e com variações influenciadas pela idade, raça, sexo, espécie, entre outros (Jain,1993).

Em relação à espécie ovina, as variações hematológicas dos animais, após processos hemorrágicos agudos, assemelham-se às de outras espécies, particularmente bovinos, evidenciadas pela diminuição abrupta dos valores hematimétricos como hemácias, hemoglobina, hematócrito, volume corpuscular médio (VCM), hemoglobina corpuscular média (HCM) e na concentração de hemoglobina corpuscular média (CHCM). Segundo Jain (1993), em ovinos os níveis de eritropoietina aumentam abruptamente a um máximo dentro de 24h e diminuem rapidamente após o terceiro dia, simultaneamente ao aumento do hematócrito e início da resposta eritropoiética da medula óssea.

Em ruminantes, a magnitude da reticulocitose é pequena, depende do grau de perda sangüínea e ainda da idade do animal; portanto, a presença de poucos reticulócitos no sangue é considerada evidência de anemia responsiva. $O$ ponteado basófilo nos ovinos é comum, principalmente durante a eritrorregeneração, e geralmente precede a macrocitose (Jain, 1986). Em experimento realizado por Winter $(1966,1967)$, foi observada reticulocitose, após perda sangüínea severa, em ovinos a partir de 72 horas.

Uma perda sangüínea aguda tem como resposta inicial uma leucocitose por neutrofilia provocada por desvio do pool marginal de neutrófilos, podendo estar associada à linfopenia e à eosinopenia. O número total pode estar aumentado concomitantemente com a resposta hematopoética pelo estímulo generalizado da medula óssea (Jain, 1993). Segundo Winter (1967), a perda de granulócitos em relação à perda sangüínea induzida não é suficiente para modificar significantemente a proporção de maturação granulocítica.

Apesar do relativo conhecimento sobre a resposta eritroleucocitária nos processos hemorrágicos há ainda alguns pontos a serem esclarecidos, como a duração da resposta medular na liberação de reticulócitos e eritroblastos para a circulação sangüínea e a dinâmica da resposta leucocitária. Assim, o presente trabalho tem como escopo contribuir para o estudo do quadro hematológico de animais da espécie ovina após perda sangüínea de cerca de $20 \%$ do volume circulante.

Correspondência para Denise Howard - Depto de Clínica Médica, Faculdade de Medicina Veterinária e Zootecnia, Universidade de São Paulo, Av. Prof. Dr. Orlando Marques de Paiva, 87 CEP 05508-900, São Paulo, SP, Brasil. 


\section{Material e métodos}

Foram utilizados 7 ovinos (5 fêmeas e 2 machos), provenientes do Hospital Veterinário da Universidade de São Paulo, com bom estado geral e isentos de doenças parasitárias. Os animais foram submetidos à venopunção jugular com retirada de estimados $20 \%$ de sangue total, calculados de acordo com dados fornecidos por Jain (1993) quando o ovino apresenta de 62 a $67 \mathrm{ml}$ de sangue por $\mathrm{kg}$ de peso corpóreo. As amostras de sangue foram colhidas nos seguintes tempos: imediatamente antes da sangria (Oh) e após 3, 6, 12, 24h e 2, 3, 4, 5 , 6, 8, 10, 12 e 14 dias.

As amostras foram colhidas em tubos Vacutainer com EDTA e realizadas as seguintes análises: avaliação qualitativa e quantitativa de hemácias e leucócitos, dosagem de hemoglobina, hematócrito, contagem de reticulócitos e cálculo dos índices hematimétricos VCM, $\mathrm{HCM} \mathrm{e} \mathrm{CHCM.}$ Esfregaços sangüíneos, para identificação dos leucócitos, foram confeccionados com gota in natura e corados com corante de Rosenfeld; nos esfregaços para contagem dos
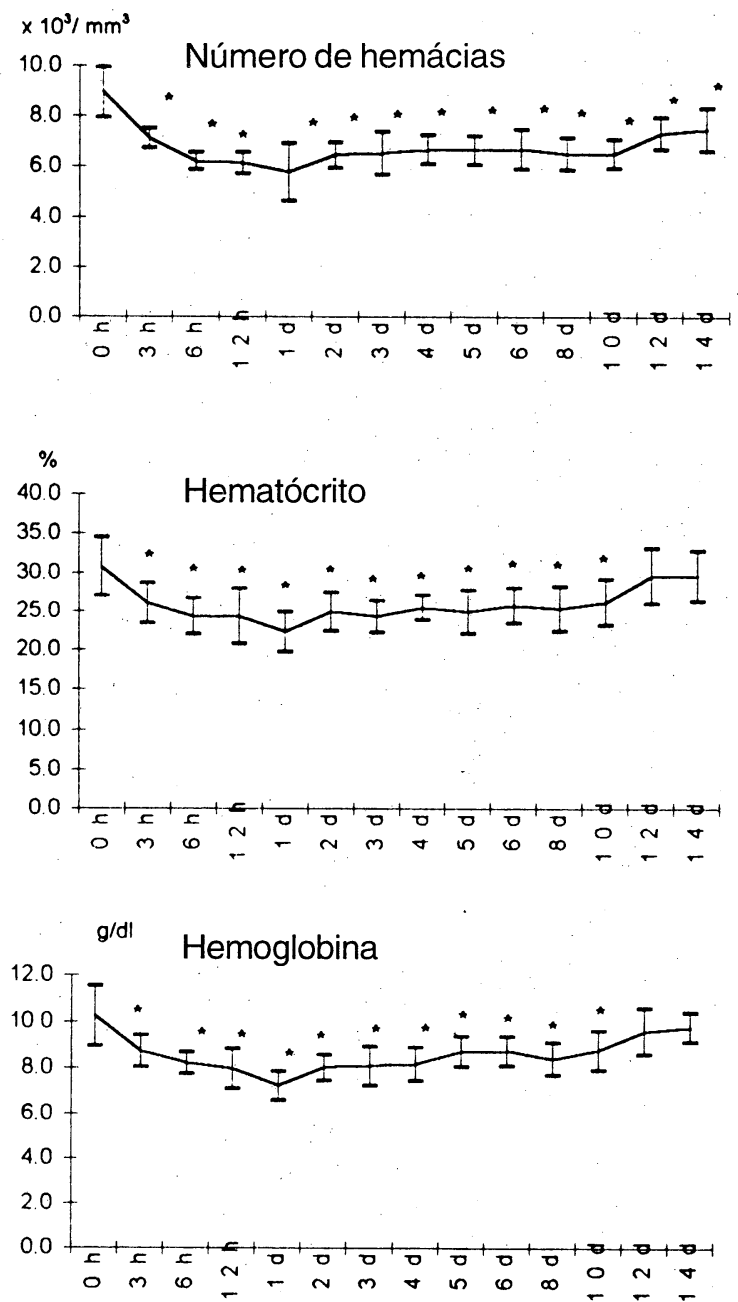

reticulócitos foi utilizado o corante vital novo azul de metileno, conforme recomendado por Birgel (1982). Os resultados foram submetidos à análise de variância, ao nível de significância de 5\%, com o teste de ANOVA.

\section{Resultados}

As variações na contagem do número de hemácias, da hemoglobina, do hematócrito, bem como o VCM, HCMe $\mathrm{CHCM}$, nos vários tempos avaliados, estão demonstrados na Figura 1. Houve diminuição significante no número de hemácias, hemoglobina e hematócrito no primeiro momento analisado (3h após sangria) em relação ao tempo Oh, com valores decrescentes até as $24 \mathrm{~h}$, quando começaram a subir. Aos 12 dias pós-sangria os valores do hematócrito e de hemoglo-bina retornaram aos níveis iniciais. Com relação ao VCM, houve diferença às 12 h e aos 10 e 12 dias pós-sangria. Observou-se, nos valores do HCM, variações semelhantes aos encontrados no VCM, todavia, às 6 e $12 \mathrm{~h}$, e a partir dos 6 dias até o final do periodo da observação.
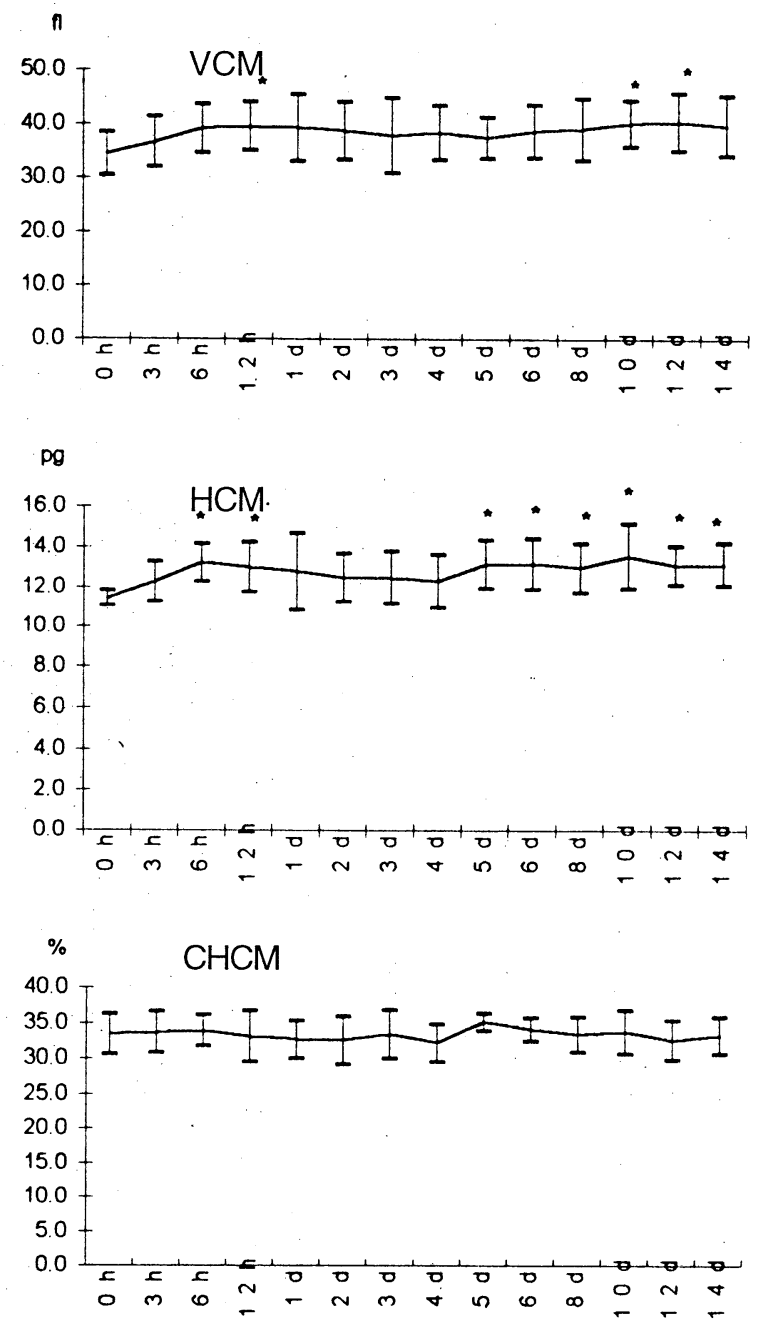

Figura 1: Representação gráfica dos valores médios e desvios padrões dos componentes do eritrograma de ovinos submetidos a uma sangria de $20 \%$ do sangue total em relação ao peso corpóreo nos diferentes tempos de Oh a 14 dias; *: estatisticamente significante (p>0,05); VCM: volume corpuscular médio; HCM: hemoglobina corpuscular média; $\mathrm{CHCM}$; concentração de hemoglobina corpuscular média. 
Os valores referentes aos eritroblastos e reticuló-citos estão representados na Figura 2. Sinais de eritrorregeneração como ponteados basófilos, policroma-sia, anisocitose e presença de eritroblastos, estavam evidentes nos esfregaços san-güíneos a partir dos 3 dias, no entanto, o número de eritroblastos não apresentou diferença entre os tempos. A contagem de reticulócitos aumentou significativamente entre 2 e 12 dias, com picos entre 3 e 6 dias pós-sangria.

Os valores do leucograma estão representados na Figura 3. O número total de leucócitos aumentou no primeiro e segundo dia após a sangria. O número total de neutrófilos sofreu aumento significante das 3 horas até aos 2 dias; os monócitos entre 3 e 6 dias e entre 8 e 12 dias, e os eosinófilos nos tempos de 1, 12 e 14 dias.

\section{Discussão}

Nas primeiras horas após a sangria (3 às $24 \mathrm{~h}$ ), houve redução do número de hemácias, da hemoglobina e do hematócrito, resultante da perda aguda de sangue em relação ao peso corpóreo (Jain,1993). A perda aguda de sangue desencadeia a liberação de reserva sangüínea tanto medular como por contração esplênica, particularmente em ovinos que apresentam reserva de cerca de um quarto do volume eritrocitário total no baço (Torrington et al.,1989). Tais fatos levam ao aparecimento de eritrócitos imaturos, maiores, no sangue periférico, causando um aumento do $\mathrm{HCM}$ entre $6 \mathrm{e}$ $12 \mathrm{~h}$ e do VCM em $12 \mathrm{~h}$ pós-sangria. Esses resultados são semelhantes aos de Winter (1966) que sugere que a reserva
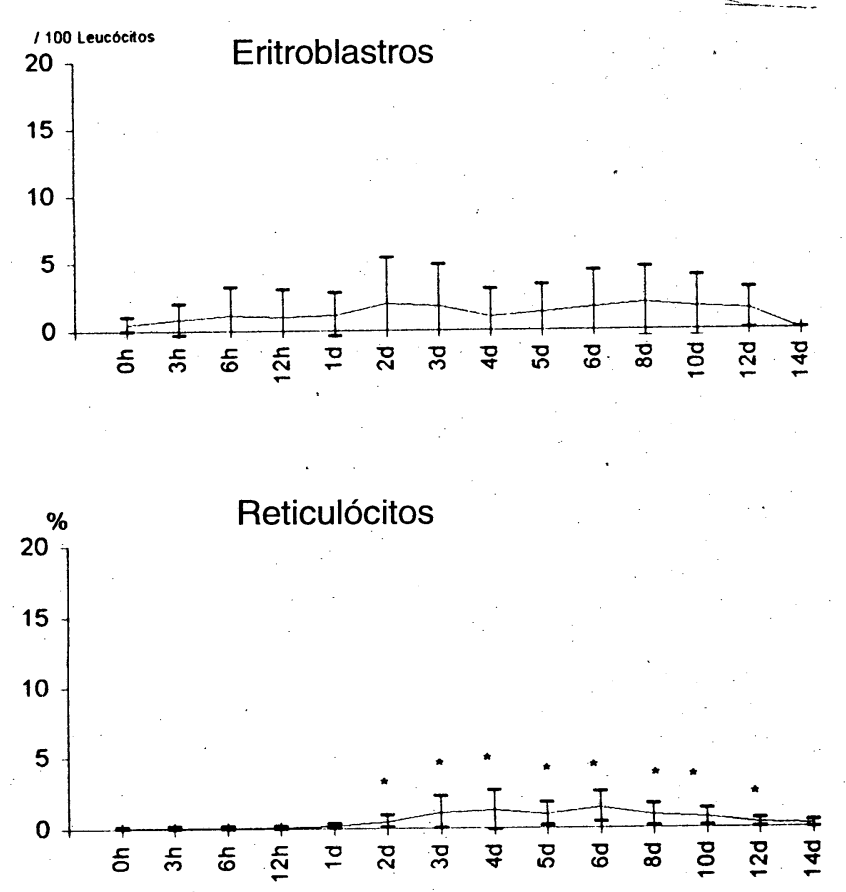

Figura 2: Representação gráfica dos valores médios e desvios padrões dos eritroblastos e reticulócitos de ovinos submetidos a uma sangria de $20 \%$ do sangue total em relação ao peso corpóreo nos diferentes tempos de oh a 14 dias; *: estatisticamente significante $(p>0,5)$. de ferro dos animais era suficiente para suprir a hemoglobina dos novos eritrócitos produzidos pelo organismo.

Em relação à resposta regenerativa do sistema hematopoiético ao distúrbio hemorrágico, observou-se que o aparecimento de reticulócitos, no presente trabalho, ocorreu a partir de dois dias pós-sangria, à semelhança das observações de Duncan (1986). Jain (1986) e Winter (1967), em trabalhos realizados em ovinos e em outras espécies, o haviam observado apenas após o terceiro dia. A liberação de reticulócitos provavelmente foi induzida pela secreção de eritropoietina após a perda sangüínea, sendo o grau de sua liberação determinado pela severidade da anemia. Os reticulócitos observados com coloração supravital estão correlacionados com o ponteado basófilo, a anisocitose e a presença de eritroblastos observados nos esfregaços corados com o corante de Rosenfeld. A eritroblastose observada em alguns animais sem, no entanto, haver uma diferença estatística entre as médias dos
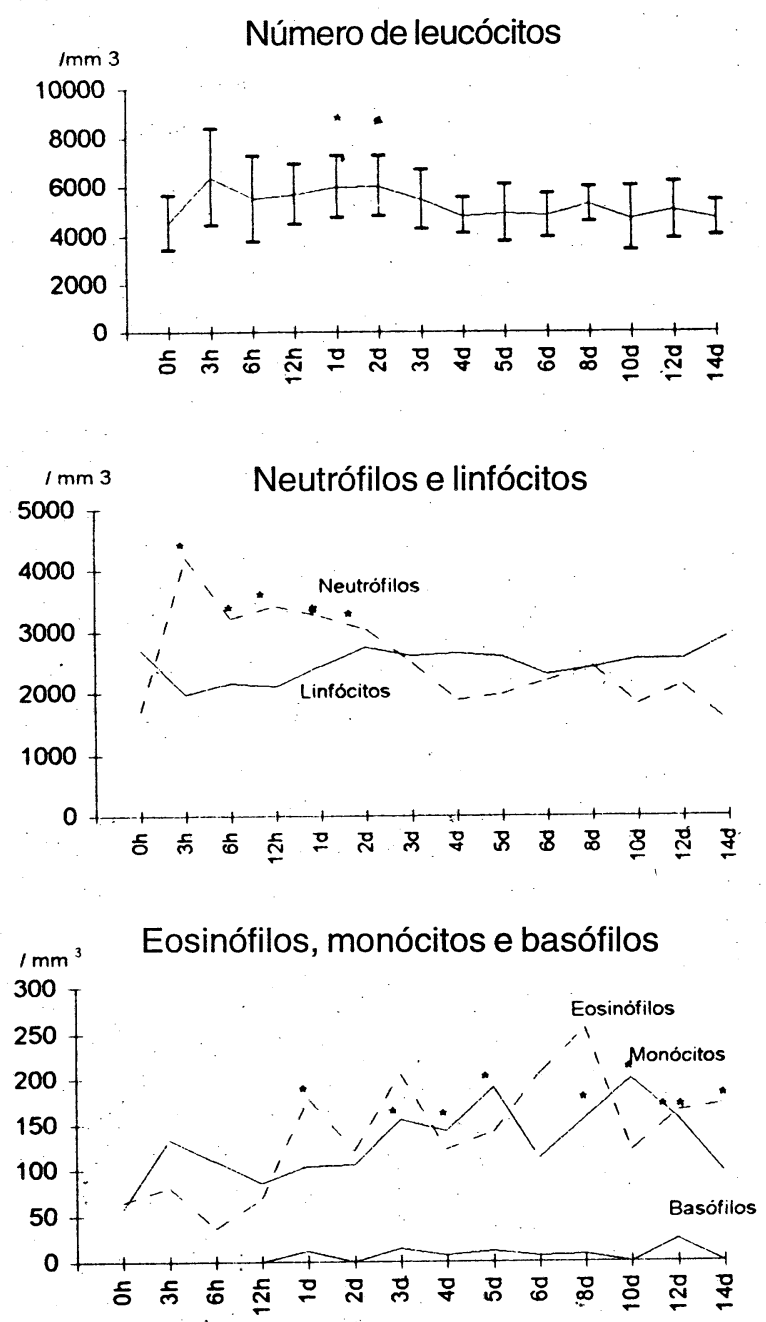

Figura 3: Representação gráfica dos valores médios e desvios padrốes dos componentes do leucograma de ovinos nos diferentes tempos (horas e dias) submetidos a uma sangria de $20 \%$ do sangue total em relação ao peso corpóreo, nos diferentes tempos de Oh a 14 dias; *: estatisticamente significante $(p>0,5)$. 
diferentes tempos, provavelmente devido ao desvio padrão muito alto, indica a existência de uma variação individual de resposta entre os animais.

O restabelecimento dos valores normais do hematócrito e da hemoglobina aos 12 dias, sem o retorno dos valores normais do número de hemácias, indica que houve macrocitose, evidenciada pelo aumento do VCM aos $10 \mathrm{e}$ 12 dias e do HCM a partir do quinto dia pós-sangria. Isto pode ser justificado pela maturação de reticulócitos em eritrócitos após a liberação da medula, que ocorre entre 24 e 48h na circulação ou no próprio baço, onde eles são seqüestrados temporariamente e perdem seu retículo, mas não deixam de estar aumentados de tamanho. O reticulócito é capaz de produzir hemoglobina e necessita-se de algumas horas para sua maturação (30h em cães); segundo Winter (1966) e Jain (1986), é a maior causa de macrocitose e do aumento do VCM.Eritrócitos grandes são observados em caprinos durante várias semanas após a perda de sangue porém sem haver reticulocitose evidente.

Quanto à resposta leucocitária, o aumento inicial de neutrófilos, com inversão da relação linfócitos: neutrófilos às 3 h pós-sangria, pode ser interpretado como resposta a uma estimulação adrenérgica desencadeada pelo distúrbio hemorrágico, em que há o deslocamento do poo/marginal de neutrófilos para a circulação geral, bem como de mobilização da reserva medular (Jain, 1993). O aumento significante do número de eosinófilos às $24 \mathrm{~h}$ deve-se, também, ao estresse adrenérgico inicial da sangria, por uma mobilização de eosinófilos do baço, e que não ocorre em ratos e cobaias esplenectomizados (Jain, 1986).

Aos 3 dias, houve o restabelecimento da relação entre linfócitos e neutrófilos, indicando o fim do período de estresse. Com o estímulo da medula óssea há produção de outras células concomitantemente à eritrorregeneração, todavia, como evidenciado por Winter (1966), não houve demanda suficiente para provocar desvio à esquerda nem aumento significativo no número de granulócitos. A resposta leucocitária medular mostrou ser muito variada entre os animais e os valores médios absolutos de monócitos, eosinófilos e basófilos aumentaram, porém, em conseqüência dos desvios padrões muito altos, houve diferença estatística apenas em relação ao número total de monócitos.

\section{Conclusão}

Conclui-se que a sangria de $20 \%$ provocou diminuição dos valores hematológicos em relação aos momentos anterioes à sangria, com posterior resposta sangüínea regenerativa, suficiente para avaliar a dinâmica hematopoiética na perda aguda de sangue nos ovinos.

\begin{abstract}
An acute blood loss of approximately $20 \%$ of total blood volume was induced in order to evaluate the hematological changes during 14 days of observation in sheep. A significant decrease in the erithrocytic parameters occurred $3 \mathrm{hr}$ after blood loss, with a peak after $24 \mathrm{hr}$, and a return to non-significant values after 12 days. Reticulocytes increased significantly between days 2 and 12, while erytroblasts did not. An inversion on the linfocyte:neutrophil rate was observed during the first 3 days due to acute blood loss stress. Intermittent eosinophilia and monocitosis occurred during the animals' recovery. It is concluded that $20 \%$ of blood loss in sheep induced acute anemia allowing an evaluation of the hematopoetic response.
\end{abstract}

Keywords: hemorrhagic anemia; ovine; hematology.

\title{
Agradecimentos
}

Aos colegas da disciplina de Pós-Graduação “Temas de Hematologia de Ruminantes”, Sґ̊ Regina Mieko Sakata Mirandola, ao Prof. Enrico Lippi Ortolani pela cessão dos ovinos, ao Prof. Fernando José Benesi e à coordenadora da disciplina, Profa Mitika Kuribayashi Hagiwara.

\section{Referências bibliográficas}

BIRGEL, E.H. Hematologia Clínica Veterinária. In: BIRGEL, E. H., BENESI, F.J. Patologia Clínica Veterinária. São Paulo : Sociedade Paulista de Medicina Veterinária, 1982.

DUNCAN, J.R., PRASSE, K.W. Veterinary Laboratory Medicine. 2nd. ed. lowa : lowa State University Press, 1986.

JAIN, N.C. Schalm's Veterinary Hematology. 4th. ed. Philadelphia : Lea \& Febiger, 1986. p. 208-224.

Essentials of Veterinary Hematology. Philadelphia : Lea \& Febiger, 1993. p. 169-173.
TORRINGTON, K. G., Mc NEIL, J.S., PHILLIPS, Y.Y., RIPPLE, G.R. Blood volume determination in sheep before and after splenectomy. Laboratory Animal Science, v. 39, no. 6, p. 598602, 1989.

WINTER, $\mathrm{H}$. Changes of the red blood cell hemogram in post hemorragic anemia in sheep. Am. J. Vet. Res. v. 27, no. 119, p. 891-897, 1966.

Myelogram of sheep in post-hemorragic anemia. Am. J. Vet. Res. v. 28, no. 126, p. 1389-1395, 1967. 